\title{
Innovative pedagogies in engineering education - preliminary findings from the teaching practices of American and Canadian educators
}

\author{
Angela van Barneveld, PhD Candidate \\ Learning Design \& Technology \\ Purdue University \\ evanbarn@purdue.edu
}

\author{
Dr. Johannes Strobel, Assistant Professor \\ Engineering Education / LDT \\ Purdue University \\ jstrobel@purdue.edu
}

\begin{abstract}
This research is focused on the experiences of Canadian and American engineering educators and their implementations of innovative pedagogies such as problem-based learning (and its variations) into their teaching practices. Educators identified several aspects related to PBL use in their context, including the key PBL components they use and the tensions that they encounter at the classroom and system level when implementing such learner-centered pedagogies. Engineering education has been undergoing reform efforts for several years. Not only have PBL approaches been deemed by research literature to be an optimal approach to develop graduate competencies and attributes, but many reform efforts utilize explicitly or implicitly key components of PBL. Implications and future research opportunities are presented.
\end{abstract}

Keywords: engineering education, problem-based learning, project-based learning, pedagogy, tensions

\section{Introduction}

Problem-based learning (PBL) is a pedagogy that, it is argued, can meet the needs of engineering education as the academy transitions to active, learner-centered approaches in contrast with the traditional, content and teacher-focused approaches [1]. Active learning pedagogies such as PBL align with the criteria set by professional accreditation bodies ([2], [3]) and research indicates that PBL supports the development of technical/process skills and competencies in a variety of disciplines [4] and in engineering students [5]. While PBL adoption is not as widespread in the United States and Canada as it is in other countries [6], it has started to establish a presence in engineering education. Several general challenges and tensions are noted in the research literature with the implementation of PBL [7]. Despite these reported tensions, engineering educators have committed to and persisted with the implementation of PBL into their teaching practice.

The purpose of this study was to capture and report on the current experiences of engineering educators who have implemented PBL into their teaching practice in a consistent and sustained manner. Since engineering education reform is an in-progress global effort, the opportunity to look at both Canadian and American PBL implementations of innovative pedagogies is opportune. That is, while American engineering schools are already in the cycle of outcomes-based program accreditation against the ABET criteria, Canadian engineering schools are earlier in the process of preparation to meet program accreditation evaluations starting in 2014. The chance to share and benefit from each others' experiences is timely.

\section{Drivers for change}

\subsection{The need for reform}

While engineering education has embarked upon a path of change, and reform, there is significant opportunity for ongoing improvement [8]. Engineering programs continue to focus on technical knowledge and skills [9] delivered primarily through lecturebased approaches that may not give enough context or practice for students to understand the application of the acquired knowledge.

\subsection{The role of engineering educators}

In the pursuit of reform, the role of engineering faculty as the implementers of pedagogical change becomes critical [10]. Faculty are, to a large extent, the instigators of reform within their classrooms and the implementers of innovative pedagogical approaches. Engineering educators tended to implement PBL of their own accord and in an incremental fashion [11]. The adoption of PBL into educators' teaching practice is important to its establishment in engineering 
education and necessitates a new way of conceptualizing teaching and learning.

\section{Definitions}

\subsection{Problem-based learning}

Problem-based learning, a learner-centered pedagogy, has been conceptually brought into the realm of engineering education under various names - problembased learning (PBL) [12], project-based learning (PjBL) [13], and problem-oriented project-based learning (POPBL) [14]. The call for increased designbased curriculum in engineering education [15] is also reflected in newer curriculum strategies such as Conceive-Design-Implement-Evaluate (CDIO) [16].

In the context of this study, the definition of PBL is informed by long-established definitions in the research literature [17], [18], but remains intentionally broad and inclusive of other problemfocused pedagogies. For the study, we described PBL in terms of the following four key components to provide participants with a base from which to ground their responses: (1) use of real world design, project, or problem scenarios, (2) have multiple possible solutions (open-ended and complex), (3) instructor takes predominant role as facilitator or guide, and (4) students engaged in active learning.

\subsection{Tensions}

For this study, tension is defined as “...a relationship between ideas or qualities with conflicting demands or implications" [19]. We deliberately chose the term tension to particularly highlight the fact that faculty perceive of being pulled between different competing ideas or realistic and ideal versions of teaching [20].

\section{Study description}

While there is agreement of the need to reform engineering education and that PBL is an optimal approach [1], change is slow and the adoption of PBL is far from widespread [21]. The purpose of this study was to capture and report on the current experiences of engineering educators who have implemented PBL into their teaching practice in a consistent and sustained manner. Our research question is: What does PBL look like in the teaching practices of Canadian and American engineering educators with regard to trends in preparation, support, and implementation? We would consider these educators to be somewhat ahead of the curve with their use of innovative pedagogies like PBL. We wanted to provide a snapshot of their teaching practices and experiences to serve as one of several possible gauges of the triumphs and challenges in preparing to meet the learning needs of 21st century engineering students.

\subsection{Method and sample}

We designed a 30-item online survey with the following sections - Demographics (12 items), PBL implementation in teaching practice (6 items), Challenges in PBL teaching practice in engineering (2 items), Tensions in PBL implementations (5 items) (forced ranking) and Tensions in engineering education (5 items) (forced ranking). The target audience was engineering educators implementing PBL in undergraduate engineering programs in the United States and Canada. We distributed the survey invitation via ASEE, CEEA, and other engineering organizations and associations. The survey was made available in both English and French for the Canadian participants. The final sample size was 313 American educators and 30 Canadian educators. The quality of the survey results is influenced by two factors: (1) response rate and (2) representation of the sample. Return rates for online surveys range from 1-5 percent of the targeted population [22]. Given that there are an estimated 25,000 engineering faculty in the United States [23] and that, expectedly, only a subset are teaching with a PBL-oriented method, the American response rate is sufficient. The variance of participating schools, different rank of faculty, and gender indicates that the sample is representative in regards to demographic factors. The Canadian sample is not strong enough for any sophisticated statistical analysis, and frequencies - as presented here - should be treated with caution.

\subsection{Demographics}

Table 1 provides an overview of the descriptive statistics related gender, age, and years of experience as an engineering educator for our final sample.

Table1: Sex, age, and years teaching engineering

\begin{tabular}{|l|c|c|c|c|c|c|c|c|}
\hline \multicolumn{4}{|c|}{ Canada $(\mathbf{n}=\mathbf{3 0})$} & \multicolumn{3}{c|}{ USA $(\mathbf{n}=\mathbf{3 1 3})$} \\
\hline & \multicolumn{2}{|c|}{ Male } & \multicolumn{2}{c|}{ Female } & \multicolumn{2}{c|}{ Male } & \multicolumn{2}{c|}{ Female } \\
\hline Sex & \multicolumn{2}{|c|}{$70 \%$} & \multicolumn{2}{c|}{$30 \%$} & \multicolumn{2}{c|}{$72 \%$} & \multicolumn{2}{c|}{$25 \%$} \\
\hline & Mean & SD & Mean & SD & Mean & SD & Mean & SD \\
\hline Age & 49.85 & 8.90 & 39.25 & 7.10 & 51.56 & 12.16 & 45.78 & 8.24 \\
\hline Yrs Teaching & 16.33 & 9.29 & 10.22 & 5.85 & 19.24 & 12.29 & 13.02 & 7.56 \\
\hline
\end{tabular}

The majority of respondents held the rank of Full or Associate Professor (CAN=64\%; USA=71\%). The 
predominant engineering domains represented in the CAN sample were Chemical (20\%), Mechanical (15\%) and Industrial (15\%), while the predominant engineering domains represented in the USA sample were Mechanical (21\%); Electrical (11\%); Civil (10\%); and Chemical (10\%).

\section{Preliminary findings}

\subsection{Program year that PBL was implemented}

Participants were asked to identify all the years of the engineering program in which they implemented PBL. While the majority of engineering educators use PBL in the senior year, USA educators make greater use of PBL in the early years of the engineering program (see Figure 1).

Figure 1. PBL implementation in program years

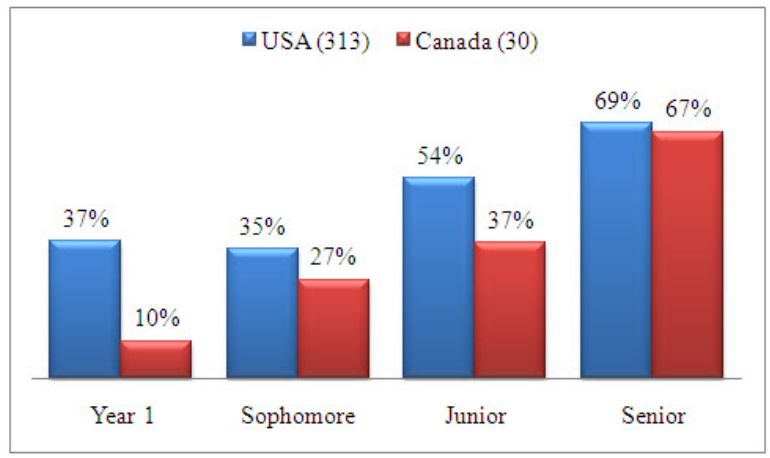

\subsection{Years experience using PBL}

The sampling strategy for this study was to intentionally seek out engineering educators who had a committed investment in making use of PBL in their teaching practice. For the educators who responded to this survey, the USA educators appear to have a longer tenure with the use of PBL (see Figure 2).

Figure 2. Years experience with PBL

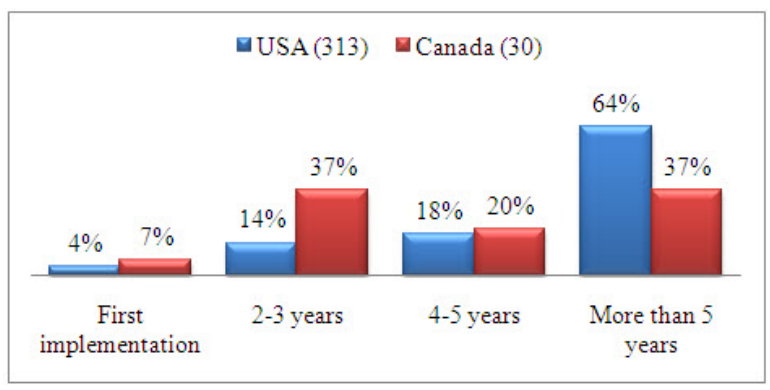

\subsection{Preparation to use PBL in teaching practice}

Participants were asked how they prepared themselves to implement PBL into their teaching practice. By far, the primary method by which both CAN and USA educators learned how to implement PBL was to selfteach. Formal training in PBL was identified as one of the least used preparatory methods (see Figure 3). An additional analysis of the Other category revealed that both CAN and USA educators made primary use of their industry experience to inform their implementations of PBL.

Figure 3. Preparation for PBL

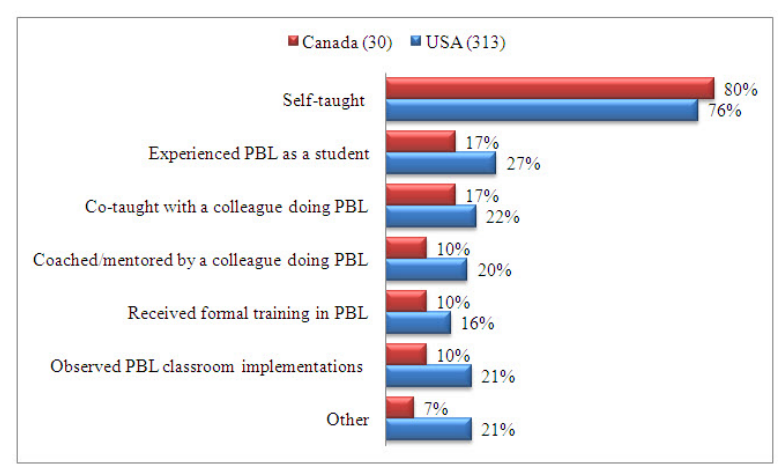

\subsection{Extent of PBL use in courses}

Participants were asked to indicate the extent to which they used PBL in their courses. The majority of engineering educators in CAN and USA implemented PBL at the module level (see Figure 4).

Figure 4: Extent of PBL use in courses

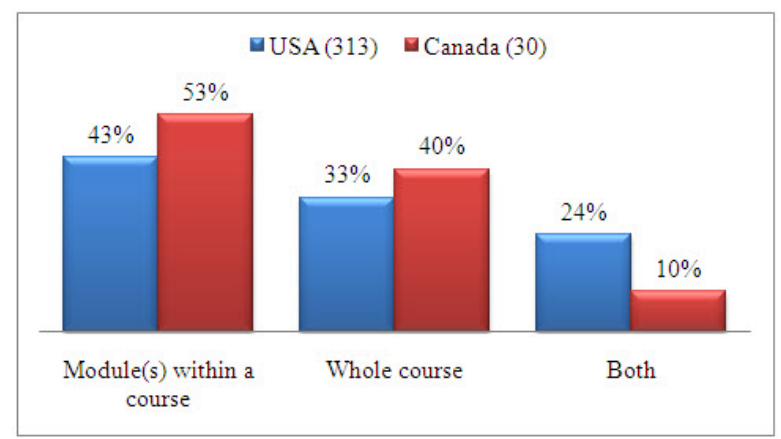

\subsection{Extent of PBL use in workload}

Participants were asked to indicate the extent to which they used PBL in their entire teaching workload (see Figure 5). 
Figure 5: Extent of PBL use in workload

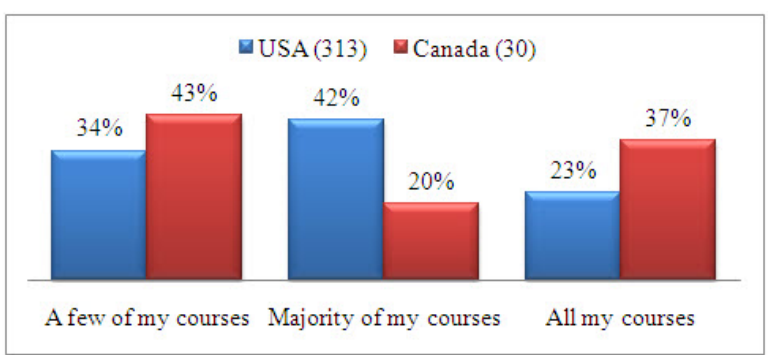

\subsection{PBL components used in teaching practice}

Participants were asked to identify the key PBL components that they use in their teaching practice. The top 3 - most used (see Table 2) and the bottom 3 - least used (see Table 3) are presented. While the most and least components used are somewhat similar between CAN and USA engineering educators, it is intriguing that reflective processes are the least used by both groups.

Table 2: Most used PBL components in practice

\begin{tabular}{|c|c|}
\hline Canada (30) & USA (313) \\
\hline 1. Activities reflect real world problems & $\begin{array}{l}\text { 1. Students are encouraged to take } \\
\text { responsibility for their ownleaming }\end{array}$ \\
\hline 2. I take the role of coach or facilitator & 2. Activities reflect real world problems \\
\hline $\begin{array}{l}\text { 3. Students are encouraged to take } \\
\text { responsibility for their own leaming }\end{array}$ & ups work as collaborative teams \\
\hline
\end{tabular}

Table 3: Least used PBL components in practice

\begin{tabular}{|l|l|}
\hline Canada (30) & USA (313) \\
\hline $\begin{array}{l}\text { 1. } \\
\begin{array}{l}\text { Students reflect on their leaming- } \\
\text { process }\end{array}\end{array}$ & 1. Students reflect on their leaming - process \\
\hline 2. $\begin{array}{l}\text { Students reflect on their leaming- } \\
\text { knowledge/skills }\end{array}$ & $\begin{array}{l}\text { 2. } \\
\begin{array}{l}\text { Students reflect on their leaming- } \\
\text { knowledge/ shills }\end{array}\end{array}$ \\
\hline 3. Self and peer assessments & 3. Problems are interdisciplinary \\
\hline
\end{tabular}

\subsection{Support for PBL in teaching practice}

Participants were asked to rate a series of support options based on how valuable they were for their implementations of PBL and the extent of adequacy of the support option. While both groups of educators rated favourable teaching and learning spaces as the most valuable support, CAN engineering educators also highly valued additional teaching assistants while USA engineering educators highly valued release time for course design. Both groups of educators rated public recognition and promotion and tenure as least valuable to them.
With regard to the adequacy of the supports that they get, both CAN and USA engineering educators rated favourable teaching and learning spaces as the most adequate, followed by additional teaching assistants for the CAN educators and budget for materials for the USA educators. Both groups of educators gave the absolute lowest rating to release time for course design with regard to how adequately it was supported.

\section{Tensions}

The research literature has identified tensions that arise at the classroom [7] and system level [16] when implementing innovative pedagogies such as PBL. What was yet to be discovered was the frequency/extent to which engineering educators using PBL actually encountered these tensions. Participants were provided with the research-based tensions and asked to force-rank them in order of frequency with which they were encountered, as well as the extent to which they thought they were successfully managing the tensions. It should be noted that the forced-choice aspect of these question provided us with data about the relative frequency of the named tensions in relation to each other. We present the top two tensions identified by participants on the assumption that their first two choices are the most deliberate.

\subsection{Tensions in PBL}

The top two PBL tensions identified by participants are presented in Table 4. The Management column reflects the extent to which participants indicated that they were successful or very successful in addressing the associated tension.

Table 4: Frequency and management of PBL tensions

\begin{tabular}{|l|l|c|}
\hline \multicolumn{2}{|c|}{ Frequency } & Management* \\
\hline Canada & 1. Student initial discomfort vs their positive attitudes & $54 \%$ \\
\hline & 2. Traditional role of instructor vs role as facilitator & $70 \%$ \\
\hline & & \\
\hline USA & 1. Student initial discomfort vs their positive attitudes & $48 \%$ \\
\hline & 2. Depth vs breadth of curriculum & $43 \%$ \\
\hline
\end{tabular}

\subsection{Tensions in engineering education reform}

The top two engineering education (system) tensions identified by participants are presented in Table 5 . The Management column reflects the extent to which participants indicated that they were successful or very successful in addressing the associated tension. 
Table 5: Frequency and management of tensions in engineering education

\begin{tabular}{|l|l|c|}
\hline \multicolumn{2}{|l|}{ Frequency } & Management* \\
\hline Canada & 1. Individual vs organizational value assigned to teaching & $36 \%$ \\
\hline & 2. Theory vs application practice & $53 \%$ \\
\hline & & \\
\hline USA & 1. Individual ys organizational value assigned to teaching & $33 \%$ \\
\hline & 2. Classroom problems vs real world problems & $66 \%$ \\
\hline
\end{tabular}

\section{Discussion}

The intent of our study was to provide an initial glimpse into the trends in the use of innovative pedagogies by engineering educators who are preparing for or already supporting outcomes-based programs.

Key PBL components used. CAN and US participants had similar ratings for the most frequently used PBL components in their teaching practice (see Table 2). CAN and US participants both identified the use of student reflections are the least used in teaching practice. Interestingly, students' use of meta-cognitive skills such as reflection on their learning process is one of the characteristics of deep learning [24], an outcome of reform efforts.

Program year of PBL implementation. As is common in engineering education, our participants reported the most frequent use of PBL in the later years of the program where the primary drivers for PBL use included the need to transfer skills, and to practice and apply generic skills and professional attitudes [25]. However, the use of PBL in the early years of engineering programs was more frequently reported by the US engineering educators. The primary drivers for PBL in freshman and sophomore years included a need to integrate process skills, to demonstrate relevance of the foundational knowledge and basic science to the practice of engineering, to engage and retain students, and to support deep learning and transfer of knowledge and skills [5].

Tensions. The engineering educators in this study reported greater success in managing tensions at the classroom level than at the system level. While tensions present opportunities for innovation [26], support for those innovations may be required at both the classroom and system level [24].

\section{Conclusion}

As engineering education reform continues to move toward outcomes-based programs, PBL has been noted to be a pedagogy poised to meet the learning needs of engineering students. The engineering educators who were part of this study have committed to PBL in their teaching practice, despite the challenges and tensions at both the classroom and system levels.

Implications. Our preliminary findings may be relevant for (1) professional development programs, carrying appropriate incentives, for educators who want to implement PBL into their teaching practice, (2) administrators/policy makers who are planning curriculum redesign to meet outcomes-based program accreditation needs and ways to support their faculty.

Limitations and future research. The CAN sample of engineering educators is smaller and less representative than the US sample. Future research is merited in that, while the survey provided trends, further insight through follow-up interviews and possibly institutional information and other extant data. Additionally, the opportunity to explore the use and impact of engineering students' reflections on learning outcomes may be a consideration in curriculum reform efforts.

\section{Acknowledgements}

We would like to express our gratitude to Dr. Ron Britton (University of Manitoba) and Dr. Claude Lague (University of Ottawa). Their interest and support of our research facilitated the data collection process in Canada.

\section{References}

[1] Felder, R. M., \& Brent, R. (2003). Designing and teaching courses to satisfy the ABET engineering criteria. Journal of Engineering Education, 92(1), 7-25.

[2] Accreditation Board for Engineering and Technology. (2009). Criteria for Accrediting Engineering Programs 20102011. http://www.abet.org/Linked\%20DocumentsUPDATE/Criteria\%20and\%20PP/E001\%201011\%20EAC $\% 20$ Criteria\%201-27-10.pdf.

[3] Canadian Engineering Accreditation Board (CEAB) (2010). Accreditation Criteria and Procedures 2010. http://www.engineerscanada.ca/e/files/Accreditation_Criteri a_Procedures_2010.pdf. 
[4] Strobel, J., \& van Barneveld, A. (2009). When is PBL more effective? A meta-synthesis of meta-analyses comparing PBL to conventional classrooms. The Interdisciplinary Journal of Problem-based Learning, 3(1), 44-58.

[5] Froyd, J., Li, X., Srinivasa, A., Bassichis, W., Hodge, J., \& Maxwell, D. (2006). How do students in a project-based first-year engineering curriculum perform in a sophomore engineering mechanics course? Paper presented at the 2006 ASEE Annual Conference \& Exposition, Chicago, IL. http://soa.asee.org/paper/conference/paper-iew.cfm?id=1319

[6] Abu Hassan , M. A., Mohd Yusof, K., Abd Hamid, M. K., Hassim, M. H., Abdul Aziz, A., \& Syed Hassan, S. A. H. (2004). A review and survey of problem-based learning application in Engineering education. Paper presented at the Conference On Engineering Education (CEE 2004).

[7] Hung, W., Bailey, J. H., \& Jonassen, D. H. (2003). "Exploring the tensions of problem-based learning: Insights from research”. New Directions for Teaching and Learning, 95, 13-23.

[8] Galloway, P. D. (2008). The 21st century engineer: A proposal for engineering education reform. Reston, VA: American Society of Civil Engineers.

[9] Trevelyan, J. (2008). Real engineering is not what you learned at school......or is it? Paper presented at the Research in Engineering Education Symposium (REES), Davos, Switzerland. http://www.engconfintl.org/8axabstracts/Session\%203A/rees 08_submission_72.pdf

[10] Barr, R. B., \& Tagg, J. (1995). From teaching to learning - a new paradigm for undergraduate education. Change, 27(6), 12-25.

[11] Inderbitzin, M., \& Storrs, D. A. (2008). Mediating the conflict between transformative pedagogy and bureaucratic practice. College Teaching, 56(1), 47-52.

[12] Brodie, L., Zhou, H., \& Gibbons, A. (2008). Steps in developing an advanced software engineering course using problem based learning. Engineering Education, 3(1), 2-12.

[13] Lima, R. M., Carvalho, D., Flores, M. A., \& van Hattum-Janssen, N. (2007). A case study on project led education in engineering: Students' and teachers' perceptions. Journal of Engineering Education, 32(3), 337347.

[14] Lehmann, M., Christensen, P., Du, X., \& Thrane, M. (2008). Problem-oriented and project-based learning (POPBL) as an innovative learning strategy for sustainable development in engineering education. European Journal of Engineering Education, 33(3), 283-295.
[15] Sheppard, S. D., Macatangay, K., Colby, A., \& Sullivan, W. M. (2009). Educating engineers: Designing for the future of the field. San Francisco, CA: Jossey-Bass.

[16] Crawley, E. F., Malmqvist, J., Östlund, S., \& Brodeur, D. R. (2007). Rethinking engineering education: The CDIO approach. New York, NY: Springer.

[17] Barrows, H. (2002). Is it truly possible to have such a thing as dPBL? Distance Education, 23(1), 119-122.

[18] Savery, J. R. (2006). Overview of problem-based learning: Definitions and distinctions. The Interdisciplinary Journal of Problem-based Learning, 1(1), 9-20.

[19] Oxford Dictionary. (2010). Tension. http://oxforddictionaries.com/view/entry/m_en_us1297767\# m_en_us1297767.

[20] Cochran-Smith, M. (1991). Learning to teach against the grain. Harvard Educational Review, 61(3), 279-310.

[21] Schertz, B. K., Goldberg, D. E., \& Hyman, K. K. (2010, April 6-9, 2010 ). Engineering education reform in a large research university: Strategies and reflections on innovation. Paper presented at the Transforming Engineering Education: Creating Interdisciplinary Skills for Complex Global Environments, 2010 IEEE, Dublin, IE.

[22] Van Bennekom, F. (2003). Statistical accuracy of a survey. http://www.greatbrook.com/survey accuracy.pdf.

[23] Engineering Trends (2007). The Number of Women Faculty in Engineering Colleges Is Increasing Rapidly (Report 0907D, September). http://www.engtrends.com/IEE/0907D.php.

[24] Litzinger, T. A., Lattuca, L. R., Hadgraft, R. G., \& Newstetter, W. C. (2011). Engineering education and the development of expertise. Journal of Engineering Education, 100(1), 123-150.

[25] Mitchell, J. E., \& Smith, J. (2008). Case study of the introduction of problem-based learning into electrical engineering. International Journal of Electrical Engineering Education, 45(2), 131-143.

[26] Barab, S. A., Barnett, M., Yamagata-Lynch, L., Squire, K., \& Keating, T. (2002). Using Activity Theory to understand the systemic tensions characterizing a technology-rich introductory astronomy course. Mind, Culture \& Activity, 9(2), 76-107. 